\title{
Tree ring variability and climate response of Abies spectabilis along an elevation gradient in Mustang, Nepal
}

\begin{abstract}
D. K. Kharal ${ }^{1}$, H. Meilby ${ }^{2}$, S. Rayamajhi ${ }^{3}$, D. Bhuju ${ }^{4}$ and U. K. Thapa ${ }^{5}$
In mountainous areas including the Himalayas, tree lines are expected to advance to higher altitudes due to global climate change affecting the distribution and growth of plant species. This study aimed at identifying the tree ring variability of Abies spectabilis (D. Don) and its response to the climate along an elevation gradient in the high Himalayas of central Nepal. Tree core samples were collected from four sites in Mustang district. All sites were located in the same valley and exposed to similar weather conditions. Out of 232 samples collected from the sites, Titi lower $(2700 \mathrm{~m})$, Titi upper $(2900 \mathrm{~m})$, Pangukhark $(3100 \mathrm{~m})$ and Lete upper (3300 m), 44, 40, 39 and 41 series were successfully cross-dated and ringwidth chronologies including 168, 79, 138 and 156 years previous to 2012 were developed, respectively. Statistically significant differences in average annual radial growth were noted among the four sites with the highest radial growth observed at mid-elevation sites. Chronological statistics based on residual chronologies for the common period revealed that $A$. spectabilis at the upper elevation site was more climate sensitive than at the other three sites. At the highest-elevation sites the correlation between pre-monsoon precipitation and tree growth was positive, and for the month of May this was statistically significant $(p<0.05)$. Moreover, spring temperature (March-June) was negatively correlated with precipitation and with tree growth at all sites, and at the upper elevation site $(3300 \mathrm{~m})$ the correlation was significant for March, April and May.
\end{abstract}

Key words: Climate change, Dendro-climatology, Himalayas, tree line species, tree growth

$\mathrm{G}$ rowth response of trees to climatic variations can be studied through the measurement of annual rings of trees growing at a particular site where climate is a limiting factor. The principle of the limiting factor states that plant growth is controlled not by the total amount of resources available but by the scarcest resources (Fritts, 1976; Speer, 2010). At the margin of a species' natural distribution range climate is usually a limiting factor for growth and, therefore, climatic effects on tree growth increase when approaching the very margin of the natural distribution range (Fritts, 1976; Schweingruber, 1996). For trees at very high altitudes (at the tree line) and in very cold regions temperature during the growth season are limiting their growth and therefore their growth is frequently found to be temperature sensitive (Peng, 2008; Körner and Paulsen, 2004).

The Himalaya region is considered one of the most sensitive and vulnerable natural environments of the world (NBS, 2002; MoE, 2010; NPC, 2010; WECS, 2002). Any changes in the climate of such regions are likely to have strong impact on their environment (ICIMOD, 2010; MoE, 2010 and 2011; NBS, 2002; WECS, 2002; WWF-Nepal, 2006). However, knowledge of climate change in the high altitude Himalayan region is very limited (Borgaonkar et al., 2008; ICIMOD, 2010; WWFNepal, 2006). Glacier retreat has been taken as one of the indicators of Himalayan climate change in the form of rising temperatures (ICIMOD, 2010; MoE, 2010). Tree line advancement, change of vegetation structure and species composition at

${ }^{1}$ Department of Forest Research and Survey, Kathmandu, Nepal, Email: deepak_kharal@yahoo.com

${ }^{2}$ Copenhagen University, Denmark

${ }^{3}$ Institute of Forestry, Tribhuvan University, Nepal

${ }^{4}$ National Academy of Science and Technology, Nepal

${ }^{5}$ Golden Gate International College, Kathmandu, Nepal 
the tree line, and stand growth dynamics are some of the biological indicators of climate change. Moreover, tree rings of the woody vegetation, especially conifer species growing at tree line altitudes of the Himalaya region, can be used to detect the climate signals that are recorded in their annual growth rings (Bräuning, 2001; Schweingruber, 1996; Yadav et al., 2004). At high altitudes the strong relationship between climate variables and tree rings can be expected to provide a good basis for dendro-climatic studies (Leal et al., 2007). Hence, tree ring records of the high altitude Himalayan region can provide valuable insight regarding Himalayan climate change and its impact on the vegetation (Borgaonkar et al., 2011).

Other than the climate observed at meteorological stations, the tree-ring variability can also be influenced by local factors such as altitude, species, tree size, site (soil, ground water), slope, and aspect, all of which may alter the effects of climatic change on tree growth (Leal et al., 2007; Oberhuber, 2004; Urbinati et al., 1997). For example, in mountainous areas the relationship between observed climate at a meteorological station and tree growth at a site located in the vicinity of the station may vary with elevation as the actual temperature and precipitation at the site vary along the altitudinal gradient. Generally a decrease of $0.6^{\circ} \mathrm{C}$ in temperature is expected on average for every 100 meter increase in elevation in alpine and sub-alpine regions (Mani, 1981). Previous studies have observed significant differences in climate-tree growth relationships along altitudinal gradients in Tibet and China (Chen et al., 2011; Peng et al., 2008; Wang et al., 2005).To understand patterns found on the southern side of the Himalayan range it is equally important to examine the influence of climate on tree growth along altitudinal gradients in the Nepalese part of Himalaya.

The number of dendroclimatic studies in Nepal Himalaya is increasing at a considerable pace (Cook et al., 2003; Sano et al., 2005; Bhuju et al., 2010; Chhetri and Thapa, 2010; Gaire et al., 2011; Dawadi et al., 2013; Thapa et al., 2013). However, so far no studies have focused on examining climate-tree growth relationships along elevation gradients in the Nepal Himalaya despite the marked gradients characterizing this region. A long annual ring width series can be an important source of reliable historical information for high altitude regions (Esper, 2000; Yadav et al., 1997), and therefore long-living woody species have a high potential for dendroclimatic studies. Among the several Himalayan conifers A. spectabilis has proved its dendroclimatic potential along the entire Himalayan range (Suzuki et al., 1990; Bhattacharyya et al., 1992; Sano et al., 2005; Gaire et al., 2011; Yadav and Singh, 2002; Yadav et al., 2004). A. spectabilis is a high altitude fir distributed from $2400 \mathrm{~m}$ to $4400 \mathrm{~m}$ and with a natural range extending from Myanmar in east to Afghanistan in west (Jackson, 1994; Stainton, 1972). Therefore, the objective of this study is to examine the relationship between tree ring variability of $A$. spectabilis and climate along an elevation gradient in the high altitude central Himalayas of Nepal.

\section{Materials and methods}

\section{Study area}

Mustang district was selected for this research study since it includes many high-altitude areas where trees grow at the extreme limits of their distribution and should thus offer appropriate sites for establishing climate-tree growth relationships (Schweingruber et al., 1992; Schweingruber, 1989). The district is located in northern part of Nepal (Fig. 1) between two great Himalayan ranges, Annapurna Himalaya in the east and Dhaulagiri in the west.

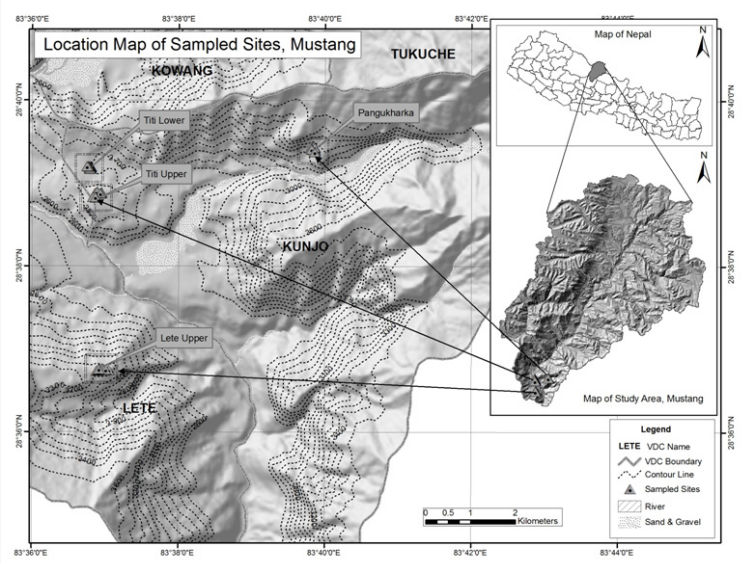

Fig. 1: Map of study area with sampled sites

The district includes large rain shadow areas with less than $200 \mathrm{~mm}$ rainfall annually, maximum temperature of $26^{\circ} \mathrm{C}$ in the summer and minimum temperature of $-20^{\circ} \mathrm{C}$ in the winter (NTNC, 2008). In fact the majority of the district's area is located in the Trans-Himalayan region where a cold desert type with semi-arid climate prevails. 
However, these areas are too dry for $A$. spectabilis and the study sites are therefore located in the southern part of the district (Lete and Kunjo VDCs), which receives more rainfall (more than $1200 \mathrm{~mm}$ annually) and where trees and forests of conifer species are distributed across a wide elevation range. Lete and Kunjo VDCs of the Mustang district were characterized by long term research area (2003-2014) under the Community based Forest Management in the Himalayas (ComForM III) Project with the establishment of 12 permanent sample plots for biophysical and socio-economic survey (Meilby et al., 2006). Only $3.24 \%$ of the total area is covered by forest and most of this forest is located in the southern part of the district around our sample sites. The forests are dominated by pine and fir in the cold temperate climatic zone, and high altitude conifer forests including $A$. spectabilis are found at different elevations. The natural resources of the areas are managed by the Annapurna Conservation Area Project (ACAP) since 1992 under the National Trust for Nature Conservation, a national nongovernmental organization (www.ntnc.org.np).

\section{Sampling design and sample collection}

Study sites were established at four different elevations ranging from the lowermost margin of the distribution of $A$. spectabilis at around $2700 \mathrm{~m}$ up to $3300 \mathrm{~m}$ elevation at the mountain ridge. Each site was identified in such a way that the site homogeneity could be maintained as suggested by Schweingruber et al. (1992). For this purpose, a strip of land with a width of $50 \mathrm{~m}$ was established across the slope direction at intervals of $200 \mathrm{~m}$ along the slope. Tree cores were collected at a height of $1.3 \mathrm{~m}$ above ground using stainless steel Swedish Increment borers of three different sizes (24", 18" and 16" long and $5 \mathrm{~mm}$ diameter). Descriptive details of the sampling sites and the number of samples collected are presented in table 1.
The sites were located within the same valley and it is therefore assumed that all four sites are exposed to almost similar weather conditions and climatic variations from year to year. Moreover, the major forest types in all sample sites were conifer-dominated, but the dominant conifer species varied between sites. Thus, the lower elevation sites (Titi lower and Titi upper) were dominated by Tsuga dumosa, whereas the upper elevation sites (Pangu and Lete upper) were mostly dominated by A. spectabilis.

\section{Sample preparation and chronology development}

Sample preparation was carried out following the standard method of tree ring analysis suggested by Cook and Kairiukstis (1992); Fritts (1976) and Schweingruber (1996). Collected samples were air dried, mounted in wooden frames and polished using sanding papers of different grit size $(80,120,240,400$ and 600$)$ until the ring boundaries were visible under microscope.

Ring widths were measured using TSAP-Win software attached to a LINTAB measuring system (version 5) operating at $0.01 \mathrm{~mm}$ resolution. The calendar year of each ring was assigned by matching the ring-width patterns of the samples of each site in TSAP-Win. The program COFECHA was used to check the accuracy of measurements and dating (Holmes, 1983). Successfully cross-dated samples were used for developing a ring-width chronology for each of the four sites located at different elevations (Table 1). Raw chronology, standard chronology, residual chronology and arstan chronology were developed using the ARSTAN computer program (Cook, 1985). The residual chronology was used for dendro-climatic analysis. This chronology was obtained after removing autocorrelation from the standard chronology by using autoregressive (AR) modelling. To obtain the standard ring-

Table 1: Description of sampling sites and number of samples

\begin{tabular}{lcrlclr}
\hline $\begin{array}{c}\text { Sampled } \\
\text { sites }\end{array}$ & $\begin{array}{c}\text { Elevation } \\
\text { range of } \\
\text { sampled sites } \\
(\mathbf{m})\end{array}$ & $\begin{array}{c}\text { Middle } \\
\text { elevation of } \\
\text { sampled sites } \\
(\mathbf{m})\end{array}$ & $\begin{array}{c}\text { Latitude } \\
\text { (northern) }\end{array}$ & $\begin{array}{c}\text { Longitude } \\
\text { (eastern) }\end{array}$ & Aspect & $\begin{array}{c}\text { Sampled } \\
\text { trees/cores }\end{array}$ \\
\hline Titi lower & $2675-2725$ & 2700 & $28.653217^{\circ}$ & $83.611113^{\circ}$ & North & $30 / 57$ \\
Titi upper & $2875-2925$ & 2900 & $28.648258^{\circ}$ & $83.612645^{\circ}$ & North & $29 / 50$ \\
Pangu khark & $3075-3125$ & 3100 & $28.657358^{\circ}$ & $83.661236^{\circ}$ & SW & $30 / 58$ \\
Lete upper & $3275-3325$ & 3300 & $28.612734^{\circ}$ & $83.613277^{\circ}$ & Ridge & $36 / 67$ \\
\hline
\end{tabular}


width chronology, natural growth trends in the tree rings that are caused by factors other than climate were removed by fitting 30 year cubic smoothing splines to each of the ring width series.

Chronology characteristics were describedby estimating various statistics, including average ring width, standard deviation, mean sensitivity and autocorrelation for the entire period among all cross-dated tree ring series. The average ring width is a robust mean which was estimated by first averaging raw chronology ring widths for each tree and then averaging the individual tree averages, thus assigning equal weights to all sampled trees. These were also estimated for the common period and, in addition, correlations of ring width within each tree, between trees and among all series were determined for the common period. Signal to Noise Ratio, expressed population signal and variability 'explained' were also estimated for the common period.

\section{Climate of the study area}

Temperature and precipitation data from local meteorological stations, common to all sample sites, were used for analysis of the climate-tree growth relationship. There are three meteorological stations in the vicinity of the sites. The stations are located in Lete, Thakmarpha and Jomsom in Mustang district. Among these, the Lete station is closest to all sample sites and located within a distance of less than $5 \mathrm{~km}$. Table 2 provides details on the three meteorological stations.

Temperature data from the station in Lete are limited to 1998-2012 which is insufficient for this study and, therefore, the Jomsom temperature data were applied for the climate-tree growth analysis. The correlation between the temperature data of Lete and Jomsom was found highly significant $(\mathrm{p} \leq 0.01)$. Precipitation data of the Lete station covered the period 1969-2012 and were found sufficient for further analysis. Figure 2 depicts the monthly distribution of temperature and precipitation in the study site.

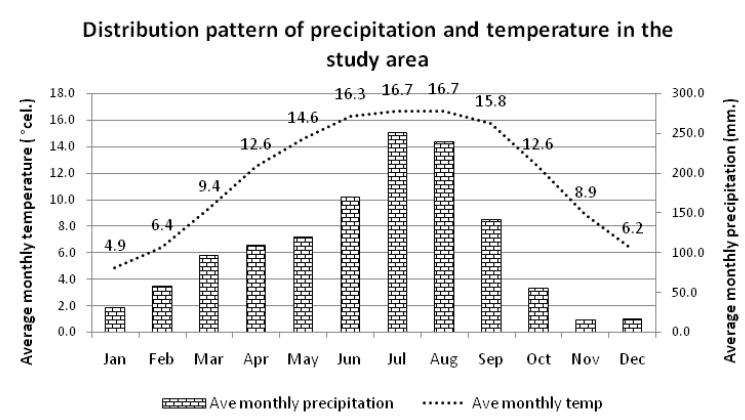

Fig. 2: Monthly distribution of precipitation and variation of temperature in the study area

\section{Climate-growth relationship}

The response of tree rings to climate fluctuations was analyzed using Pearson correlation coefficients. Correlations of the residual chronology with temperature and precipitation in different months were calculated for all sample sites with the help of the statistical software package SPSS.

\section{Results and discussion}

Out of the total set of collected samples, 44, 40, 39 and 41 tree ring series from Titi lower, Titi upper, Pangukhark and Lete upper sites, respectively, were successfully cross-dated. Samples that were broken during handling and those that were difficult to date were discarded. Table 3 shows descriptive information on radial growth of $A$. spectabilis at the four sites at different elevations. The robust average of tree ring width of $A$. spectabilis was found to be higher at the two sites in the middle of the elevation range (Titi upper and Pangu Khark) than at the other two sites at the ends of the elevation range. At the site at $3300 \mathrm{~m}$ elevation the average ring width was just about $1.54 \mathrm{~mm}$. Average annual radial increment was about $5 \%$ at the 'Titi upper' site where the average annual rate of change in increment was only about $-1.9 \%$. The annual rate of change in radial growth was found to be smallest $(-0.3 \%)$ at the site of highest elevation ( $3300 \mathrm{~m})$, presumably

Table 2: Meteorological stations in Mustang district

\begin{tabular}{lrrrrr}
\hline $\begin{array}{c}\text { Meteorological } \\
\text { stations }\end{array}$ & $\begin{array}{c}\text { Elevation } \\
(\mathbf{m})\end{array}$ & $\begin{array}{c}\text { Latitude } \\
\text { (deg/min) }\end{array}$ & $\begin{array}{c}\text { Longitude } \\
\text { (deg/min) }\end{array}$ & $\begin{array}{c}\text { Span of } \\
\text { precipitation } \\
\text { data (years) }\end{array}$ & $\begin{array}{c}\text { Span of } \\
\text { temperature } \\
\text { data (years) }\end{array}$ \\
\hline Lete, Mustang & 2384 & $28.38^{\circ}$ & $83.36^{\circ}$ & $1969-2012=43$ & $1998-2012=14$ \\
Marpha, Mustang & 2566 & $28.45^{\circ}$ & $83.42^{\circ}$ & $1967-2012=45$ & $1969-2012=43$ \\
Jomsom, Mustang & 2754 & $28.47^{\circ}$ & $83.42^{\circ}$ & $1957-2012=55$ & $1959-2012=53$ \\
\hline
\end{tabular}


Table 3: Descriptive information on ring width of $A$. spectabilis by elevation

\begin{tabular}{lccccccc}
\hline \multirow{2}{*}{$\begin{array}{c}\text { Sample } \\
\text { sites (m) }\end{array}$} & N & \multicolumn{4}{c}{ Ring width (mm) } & \multicolumn{3}{c}{$\begin{array}{c}\text { Mean annual } \\
\text { radial increment }\end{array}$} & $\begin{array}{c}\text { Mean annual } \\
\text { rate of change of } \\
\text { increment (\%) }\end{array}$ \\
\cline { 3 - 8 } & & Min & Max & Ave & Std. & 2.22 & -2.52 \\
2700 & 44 & 1.06 & 3.45 & 2.07 & 1.11 & 5.03 & -1.95 \\
2900 & 40 & 1.25 & 3.62 & 2.27 & 1.23 & 2.75 & -2.62 \\
3100 & 39 & 1.18 & 4.16 & 2.21 & 1.01 & 2.74 & -0.29 \\
3300 & 41 & 0.81 & 2.68 & 1.70 & 0.85 & & \\
\hline
\end{tabular}

reflecting the relatively low average annual radial increment $(2.7 \%)$ and the long span of years covered by many series at this site. Differences in average ring width along the elevation gradient were statistically significant (ANOVA, $\mathrm{p}<0.001$ ). Hence climatic conditions, possibly including low temperature, associated with high elevations might be limiting the growth of the trees at the high-elevation site $(3300 \mathrm{~m})$ to a greater extent than at lower elevation sites.

Statistical information on the ring width chronologies prepared for A. spectabilis at the four different sites (elevations) is shown in table 4. Based on the common period the mean sensitivity of the residual chronology was higher at the upper elevation site $(3300 \mathrm{~m})$ and lowest in lower elevation sites (2700 and
$2900 \mathrm{~m}$ ). However, the pattern of variation of mean sensitivity along the elevation gradient was found to be reversed for the overall period of the tree ring series. The reason for this presumably is that for three sites $(2700,3100$ and $3300 \mathrm{~m}$ elevation) about half of the span of years covered by the chronologies were based on very few samples $(<5$ sample trees) leading to high fluctuation in the ring width data and presumably inflating the mean sensitivity statistic. Nevertheless, this sort of pattern was also noticed in parts of China and Europe (Dittmar et al., 2012; Cai and Liu, 2013; Liu et al., 2013). The variation of the mean sensitivity was found highly significant (ANOVA, $\mathrm{p} \leq 0.001$ ).

The standard deviations of the tree ring chronologies (common period) followed a

Table 4: Statistics of ring width chronologies of $A$. spectabilis in four elevation sites

\begin{tabular}{crrrr}
\hline \multirow{2}{*}{ Statistics } & \multicolumn{4}{c}{ Elevation sites $(\mathbf{m})$} \\
\cline { 2 - 5 } Overall period & \multicolumn{1}{c}{$\mathbf{2 7 0 0}$} & $\mathbf{2 9 0 0}$ & $\mathbf{3 1 0 0}$ & \multicolumn{1}{c}{$\mathbf{3 3 0 0}$} \\
Tree/Series & $\mathbf{1 8 4 5}-\mathbf{2 0 1 2}$ & $\mathbf{1 9 3 4}-\mathbf{2 0 1 2}$ & $\mathbf{1 8 7 5}-\mathbf{2 0 1 2}$ & $\mathbf{1 8 5 7 - \mathbf { 2 0 1 2 }}$ \\
MS & $26 / 44$ & $23 / 40$ & $26 / 39$ & $26 / 41$ \\
SD & 0.248 & 0.172 & 0.140 & 0.156 \\
AC/SC & 0.248 & 0.177 & 0.139 & 0.151 \\
Common period & 0.113 & 0.166 & -0.002 & 0.102 \\
MS & $\mathbf{1 9 6 1} \mathbf{2 0 1 2}$ & $\mathbf{1 9 6 4}-\mathbf{2 0 0 9}$ & $\mathbf{1 9 6 1}-\mathbf{2 0 1 0}$ & $\mathbf{1 9 4 1}-\mathbf{2 0 1 2}$ \\
SD & 0.209 & 0.205 & 0.209 & 0.227 \\
AC/SC & 0.196 & 0.165 & 0.189 & 0.216 \\
Ra & 0.080 & -0.175 & -0.014 & 0.020 \\
Rb & 0.371 & 0.231 & 0.235 & 0.283 \\
Rw & 0.365 & 0.224 & 0.233 & 0.279 \\
SNR & 0.631 & 0.572 & 0.310 & 0.508 \\
EPS & 24.140 & 11.740 & 11.340 & 13.830 \\
Var. explained & 0.960 & 0.922 & 0.919 & 0.933 \\
\hline
\end{tabular}

Note: MS: Mean sensitivity; SD: Standard deviation; AC/SC: Autocorrelation/Serial correlation; Ra: Correlation among all series; Rb: Correlation between trees; Rw: correlation within trees; SNR; signal to noise ratio; EPS: Expressed population signal. 
similar trend along the elevation gradient as the mean sensitivity, i.e. the highest value was found at the upper elevation site $(3300 \mathrm{~m})$ and the lowest value at one of the lower elevation sites $(2900 \mathrm{~m})$. The first order auto-correlation varied greatly between sites. Higher absolute levels of auto-correlation were observed at the lower elevation sites $(2700$ and $2900 \mathrm{~m})$ and lower levels were found at upper elevation sites (3100 $\mathrm{m}$ and $3300 \mathrm{~m}$ ). The mean values of MS, $\mathrm{SD}$ and $\mathrm{AC}$ for the common periods in standard chronology were different and the variation of these statistics was highly significant among the four sites (ANOVA; $p \leq 0.001$ for all values). The
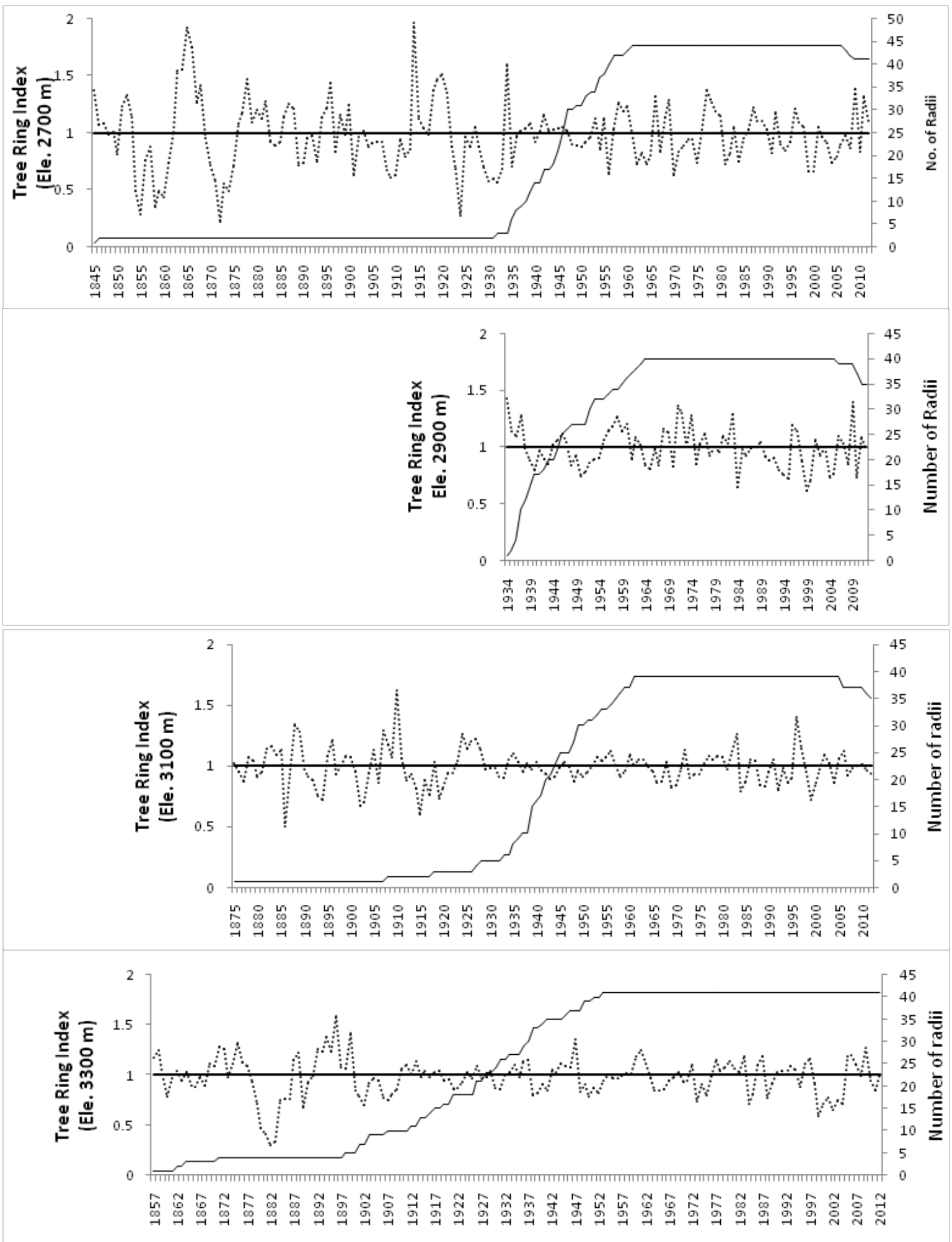

Fig. 3: Ring-width chronology of $A$. spectabilis in four sites along an elevation gradient in Mustang 
values of MS and SD observed for the common period indicate that trees at higher elevation sites are slightly more sensitive to the climate than trees at lower elevation.

Correlation coefficients of ring-widths among all trees and between trees were slightly higher at $2700 \mathrm{~m}(\sim 0.37)$ than at the other three sites $(\sim 0.22-0.28)$. The correlation coefficient within tree was high and similar at three sites $(\sim 0.50-0.63)$ but comparatively lower $(\sim 0.31)$ at the $3100 \mathrm{~m}$ elevation site. Similar correlation coefficients have been reported in other tree ring studies from the Himalaya region (Sano et al., 2005; Bhuju et al., 2010; Chhetri and Thapa; 2010; Gaire et al., 2011; Dawadi et al., 2013; Thapa et al., 2013). The Expressed Population Signal (EPS) of the chronologies of all four sites exceeded the suggested threshold limit of $0.85 \%$, indicating that the chronologies developed from the available sample size represented the site chronologies of the respective elevations well (Wigley et al., 1984). Figure 3 depicts the distribution pattern of standard chronology in four elevation sites in the study area.

\section{Climate-Tree growth relationship}

A positive relationship was observed between tree growth and May precipitation in all elevation sites in the study area (Fig. 4), but the relationship was statistically significant only at $3100 \mathrm{~m}$ $(\mathrm{p}=0.007)$ and $3300 \mathrm{~m}(\mathrm{p}=0.011)$ elevation. Similarly, correlation between tree growth and March precipitation was also positive in three elevation sites except $3300 \mathrm{~m}$, whereas in April, positive association was only noticed in upper most elevation site $(3300 \mathrm{~m})$. In most of the previous studies in Nepal and India Himalaya, pre-monsoon precipitation was also found to influence radial growth of the species positively and significantly (Sano et al., 2005; Chhetri and Thapa, 2010; Gaire et al., 2011; Dawadi et al., 2013; Thapa et al., 2013; Borgaonkar et al., 1999; Pant et al., 2000; Yadav and Singh, 2002; Yadav et al., 2004; Borgaonkar et al., 2011; Ahmed et al., 2011). Figure 4 further reveals that the ringwidth showed a clear negative relationship with the precipitation of the June and July for all sites but no such clear and strong association were observed during the end of Monsoon. The precipitation signal was captured more strongly at the higher elevation site $(3300 \mathrm{~m})$ than at lower elevations (both positive and negative effects).
However, with regard to winter precipitation the relationships were weak and varied between sites. This indicates that the winter precipitation does not influence tree growth much in our study area. Precipitation values of the October, November and December were considered from the previous year whereas rest of the precipitation values were taken from the current growth year.

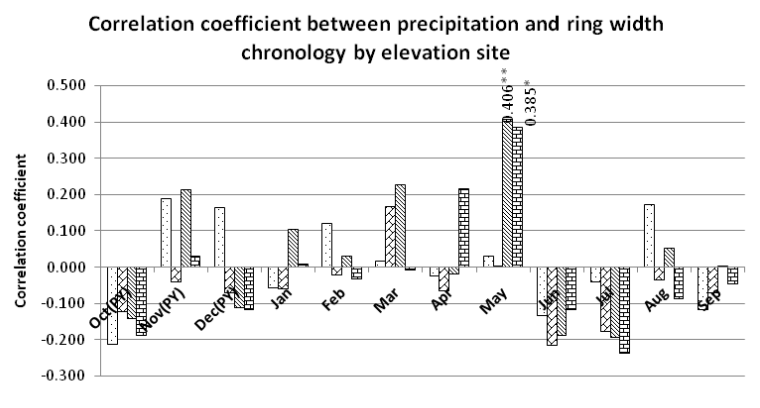

$\square r_{-} 2700 \mathrm{~m} \quad \square r_{-} 2900 \mathrm{~m} \quad \mathbb{} r_{-} 3100 \mathrm{~m} \quad \square r_{-} 3300 \mathrm{~m}$

Note: $*=$ significant at the $5 \%$ level; $* *=$ significant at the $1 \%$ level; PY=Previous Year

Fig. 4: Relationship between monthly precipitation and tree growth by elevation site

Figure 5 shows the relationship between temperature and tree growth in the study area. Spring and summer temperatures (March, April, May and June) were negatively correlated with tree growth at all sites. However, the relationship was only significant $(p \leq 0.05)$ in three months of the pre-monsoon period (March-May) for the upper elevation site $(3300 \mathrm{~m})$ and in one month (April) for lower-elevation sites (2700-2900 m). In the late summer (August) the correlation between growth and temperature was only significant at the lower boundary of the species distribution $(2700 \mathrm{~m})$.

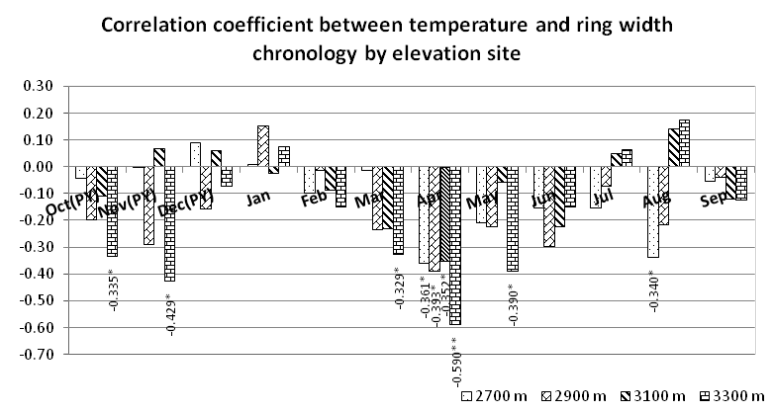

Fig. 5: Relationship between temperature and tree growth by elevation sites

Note: $*=$ significant at the $5 \%$ level; $* *=$ significant at the $1 \%$ level; PY=Previous Year

Pre-monsoon temperature was also found to be negatively correlated with growth of trees in other parts of the Himalayan range (Sano et al., 2005; Chhetri and Thapa, 2010; Gaire et al., 
2011, Dawadi et al., 2013; Thapa et al., 2013; Borgaonkar et al., 1999; Pant et al., 2000; Yadav et al., 2004; Borgaonkar et al., 2011; Ahmed et al., 2011).

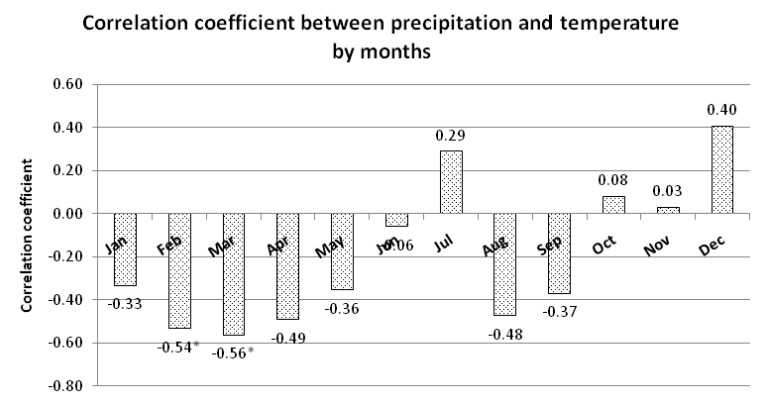

Fig. 6: Correlation between monthly precipitation and average monthly temperature

Note: $*=$ significant at the $5 \%$ level, $* *=$ significant at the $1 \%$ level

The only cases where temperature was positively but non-significantly correlated with growth were in the mid-winter (January) and mid-rainy seasons (July and August). Immediately this may appear peculiar, in as much as we would expect high-altitude trees to respond positively to higher temperatures, particularly if higher temperatures are experienced in spring or late autumn and would therefore seem to lead to extension of the growth season of the trees. However, a possible (partial) reason for the observed pattern is that temperature is correlated with precipitation. Therefore correlations between monthly precipitation and average temperature are explored in figure 6. It appears that correlations between monthly average temperature and monthly precipitation are generally negative before and after the monsoon but only significant for the months of February and March, implying that warm conditions are also comparatively dry conditions. This pattern is observed throughout the pre-monsoon season in the study area and the fact that trees appear to be responding negatively to temperature and positively to precipitation in the pre-monsoon period thus seems to indicate that growth is limited by water availability rather than temperature, at least in the pre-monsoon period.

\section{Conclusion}

In the study area in Mustang the lower and upper boundaries of the species distribution were characterized by lower radial growth rate compared to the mid-range of the species' distribution. The annual rate of change in radial growth was found to be smallest at the upper elevation site $(3300 \mathrm{~m})$. Trees at the upper boundary of the species distribution were more sensitive to the climatic conditions than trees at lower elevation sites (based on the common period of the residual chronology). The correlations between precipitation and growth were in most cases low, and while pre-monsoon correlations were positive for higher elevation sites, they were only significant in May, and only at the two highest-level sites. Spring and summer temperature had negative correlation with the tree growth in all elevation sites. Negative correlation between precipitation and temperature of the premonsoon season revealed that at this time of the year the precipitation is the main limiting factor for tree growth in all elevation sites.

\section{Acknowledgements}

This research was pursued under a $\mathrm{PhD}$ research scholarship funded by the Community based Forest Management in the Himalayas (ComForM III) Project, a joint initiative of University of Copenhagen, Denmark, Institute of Forestry and Department of Forest Research and Survey, Nepal. We are very grateful to Mr. Rabindra Maharjan, District Forest Officer, Dolakha, for his company and help in map preparation, field work and sample preparation. We would also like to thank Mr. Narayan Gaire, PhD scholar, Tribhuvan University, Nepal for providing suggestions regarding organization of field work, sample collection, sample preparation and sample measurement. We are indebted to the National Academy of Science and Technology (NAST, Nepal) who provided laboratory facilities for tree ring measurement. Finally, we acknowledge the Annapurna Conservation Area Project (ACAP, Nepal) for providing permission to carry out the field work.

\section{References}

Ahmed, M., Palmer, J., Khan, N., Wahab, M., Fenwick, P., Esper, J. and Cook, E. R. 2011. The dendroclimatic potential of conifers from the northern Pakistan. Dendrochronologia 29: $77-78$.

Bhattacharyya, A. and Chaudhary, V. 2003. Latesummer temperature reconstruction of the Eastern Himalayan region based on tree-ring data of Abies densa. Arctic, Antarctic and Alpine Research 35 (2): 196-202. 
Bhuju, D. R., Career, M., Gaire, N. P., Soraruf, L., Riondato, R., Salerno, F. and Maharjan, S. R. 2010. Dendroecological study of high altitude forest at Sagarmatha National Park, Nepal. In Contemporary Research in Sagarmatha (Mt. Everest) Region, Nepal (eds.) Jha, P. K. and Khanal, I. P., Nepal Academy of Science and Technology, Lalitpur, Nepal, 119-130.

Borgaonkar, H. P., Pant, G. B and Kumar, K. R. 1999. Tree-ring chronologies from Western Himalaya and their dendroclimatic potential. IAWA Journal 20 (3): 295-309.

Borgaonkar, H. P., Ram, S. and Sikder, A. B. 2008. Assessment of tree-ring analysis of high-elevation Cedrus deodara D. Don from Western Himalaya (India) in relation to climate and glacier fluctuations. Dendrochronologia 27: 59-69.

Borgaonkar, H. P., Ram, S. and Sikder, A. B. 2011. High altitude forest sensitivity to the recent warming: A tree-ring analysis of conifers from Western Himalaya, India. Quaternary International 236: 158-166.

Bräuning, A. 2001. Climate history of the Tibetan Plateau during the last 1000 years derived from a network of Juniper chronologies. Dendrochronologia 19 (1): 127-137.

Cai, Q. and Liu, Y. 2013. Climatic response of three tree species growing at different elevations in theLüliang Mountains of Northern China. Dendrochronologia 31: 311-317.

Chhetri, P. K. and Thapa, S. 2010. Tree ring and climate change in Langtang National Park, Central Nepal. Our Nature 8: 139-143.

Chen, L., Shaohong, W. and Pan, T. 2011. Variability of climate-growth relationships along an elevation gradient in the Changbai Mountain, northeastern China. Trees 25: 1133-1139.

Cook, E. R. 1985. A Time Series Analysis Approach to Tree Ring Standardization. Dissertation, University of Arizona, Tucson, AR, USA.

Cook, E. R. and Kairiukstis, L. A. 1990. Methods of Dendrochronology: Applications in the Environmental Sciences. Kluwer Academic Publishers, The Netherlands.

Cook, E. R., Krusic, P. J. and Jones, P. D. 2003. Dendroclimatic signals in long-tree chronologies from the Himalayas of Nepal. International Journal of Climatology 23: 707-732.

Dawadi, B., Liang, E., Tian, L., Devkota, L. P. and Yao, T. 2013. Pre-monsoon precipitation signal in tree rings of timberline Betulautilis in the Central Himalayas. Quaternary International 283: 72-77.

Dittmar, C., Eißing, T. and Rothe, A. 2012. Elevation-specific tree-ring chronologies of Norway spruce and Silver fir in Southern Germany. Dendrochronologia 30: 73-83

Esper, J. 2000. Long-term tree-ring variations in Juniperus at the upper timber-line in the Karakorum (Pakistan). The Holocene 10 (2): 253-260.

Fritts, H. C. 1976. Tree Rings and Climate. Academic Press, London, UK.

Gaire, N. P., Dhakal, Y. R., Lekhak, H. C., Bhuju, D. R. and Shah, S. K. 2011. Dynamics of Abies spectabilis in relation to climate change at the treeline ecotone in Langtang National Park. Nepal Journal of Science and Technology 12: 220-229.

Holmes, R. L. 1983. Computer assisted quality control in tree-ring dating and measurement. Tree-Ring Bulletin 43: 69-78.

ICIMOD. 2010. The Glaciers of the Hindu Kush-Himalayan Region: A Summary of the Science Regarding Glacier Melt/ Retreat in the Himalayan, Hindu Kush, Karakoram, Pamir, and Tien Shan mountain ranges.

Jackson, J. K. 1994. Manual of Afforestation in Nepal. Kathmandu: Forest Research and Survey Centre, 2nd edition, Kathmandu, Nepal.

Köerner, C. and Paulsen, J. 2004. A world-wide study of high altitude treeline temperatures. Journal of Biogeography 31: 713-732.

Leal, S., Melvin, T. M., Grabner, M., Wimmer, R. and Briffa, K. R. 2007. Tree ring-growth variability in the Austrian Alps: The influence of site, altitude, tree species and climate. Boreas 36: 426-440.

Liu, J., Qin, C. and Kang, S. 2013. Growth response of Sabina tibetica to climate factors along an elevation gradientin south Tibet. Dendrochronologia 31: 255-265. 
Mani, A. 1981.The climate of Himalaya. In The Himalaya: Aspects of Changes (eds.) Lall, J. S. and Moddie, A. D., Oxford University Press, New Delhi, 3-15.

Meilby, H., Puri, L. Christensen, M. and Rayamajhi, S. 2006. Planning a system of permanent sample plots for integrated long term studies of community-based forest management. Banko Janakari 16 (2): 3-11.

MoE. 2010. National Adaptation Programme of Action (NAPA). Ministry of Environment. Government of Nepal, Kathmandu, Nepal.

NBS. 2002. National Biodiversity Strategy Nepal. Government of Nepal, Kathmandu, Nepal.

NPC. 2010. Three Years Development Plan.National Planning Commission. Government of Nepal. Kathmandu, Nepal.

NTNC. 2008. Sustainable Development Plan of Mustang, 2008-2013. NTNC, GoN and UNEP, Kathmandu, Nepal.

Oberhuber, W. 2004. Influence of climate on radial growth of Pinus cembra within the alpine timberline ecotone. Tree Physiology 24: 291-301.

Pant, G. B., Kumar, K. R., Borgaonkar, H. P., Okada, N., Fujiwara, T. and Yamashita, K. 2000. Climatic response of Cedrus deodara tree-ring parameters from two sites in the Western Himalaya. Canadian Journal of Forest Research 30: 1127-1135.

Peng, J., Gou, X., Chen, F., Li, J., Liu, P. and Zhang, Y. 2008. Altitudinal variability of climate-tree growth relationships along a consistent slope of Anyemaqen Mountains, northeastern Tibetan Plateau. Dendrochronologia 26: 87-96.

Sano, M., Furuta, F., Kobayashi, O. and Sweda, T. 2005. Temperature variations since the mid-18th century for Western Nepal, as reconstructed from tree-ring width and density of Abies spectabilis. Dendrochronologia 23: 83-92.

Schweingruber, F. H. 1989. Tree Rings: Basics and Applications of Dendrochronology. Kluwer Academic Publishers, The Netherlands.

Schweingruber, F. H. 1996. Tree Rings and Environment: Dendroecology.
Birmensdorf, Swiss Federal Institute for Forest, Snow and Landscape Research. Berne, Stuttgart, Vienna, Haupt.

Speer, J. H. 2010. Fundamentals of tree-ring research. The University of Arizona Press, Tucson.

Stainton, J. D. A. 1972. Forests of Nepal. The Camelot Press Ltd and Southampton, London.

Suzuki, E. 1990. Dendrochronology in coniferous forests around Lake Rara, West Nepal. Botanical Magazine Tokyo 103: 297-312.

Thapa, U. K., Shah, S. K., Gaire, N. P., Bhuju, D. R., Bhattacharyya, A. and Thagunna, G. S. 2013. Influence of climate on radial growth of Abies pindrow in Western Nepal Himalaya. Banko Janakari 23 (2): 14-19.

Urbinati, C., Carrer, M. and Sodiro, S. 1997. Dendroclimatic response variability of Pinus cembra L. in upper timberline forests of Italian eastern Alps. Dendrochronologia 15: 101-117.

Wang, T., Ren, H. B. and Ma, K. P. 2005. Climatic signals in tree ring of Piceas chrenkiana along an altitudinal gradient in the central Tianshan Mountains, northwestern China. Trees 19: 735-741.

WECS. 2005. National Water Plan. Water and Energy Commission Secretariat, Government of Nepal. Kathmandu, Nepal.

WECS. 2002. Water Resources Strategy Nepal. Water and Energy Commission Secretariat, Government of Nepal. Kathmandu, Nepal.

Wigley, T. M. L., Briffa, K. R. and Jones, P. D. 1984. On the average value of correlated time series, with applications in dendroclimatology and hydrometeorology. Journal of Climate and Applied Meteorology 23: 201-213.

WWF-Nepal. 2006. An Overview of Glaciers, Glaciers Retreat, and its Subsequent Impacts in Nepal, India and China. Kathmandu, Nepal.

Yadav, R. R. and Singh, J. 2002. Tree-ring analysis of Taxus baccata from the Western Himalaya, India, and its dendroclimatic potential. TreeRing Research 58 (1/2): 23-29.

Yadav, R. R., Singh, J., Dubey, B. and Chaturvedi, R. 2004. Varying strength of relationship between temperature and growth of high- 
level fir at marginal ecosystems in western Himalaya, India. Current Science 86 (8): 1152-1156.

Yadav, R. R., Park, W. K. and Bhattacharyya, A. 1997. Dendroclimatic reconstruction of April-May temperature fluctuations in the western Himalaya of India since A.D. 1698. Quaternary Research 48: 187-191.

Yasue, K., Noda, M., Kobayashi, O., Sano, M., Kato, T. and Sweda, T. 2002. Dendroclimatological potential of Abies spectabilis at Khurpudada pass, Ganesh Himal, Central Nepal. In Geothermal/ Dendrochronological Paleo climate Reconstruction across Eastern Margin of Eurasia. Proceeding 2002 International Mastsuyama Workshop, pp. 20. http://www. ntnc.org.np as of Oct. 30, 2011. 